\title{
Propagation Models and their Applications in Digital Television Broadcast Network Design and Implementation
}

\author{
Armoogum V., Member IEEE, University of Technology, Mauritius \\ Soyjaudah K.M.S., University of Mauritius, Mauritius \\ Mohamudally N., University of Technology, Mauritius \\ Fogarty T., London South Bank University
}

\section{Introduction}

In this work, we will discuss the importance of propagation models when designing new broadcast networks. We will hence consider the Island of Mauritius as a case study. Mauritius is a tropical island, located in the Southern Hemisphere with geographic coordinates $20^{\circ} 17^{\prime} \mathrm{S}, 57^{\circ} 33^{\prime} \mathrm{E}$ and has two climates. A humid and subtropical climate dominates and becomes more effective below the 400-meter level on most of the southeastern side of the island as well as below 450 meters on the leeward side. Above these altitudes, the climate is more temperate (Metz 1994). The island has two seasons. Summer is hot and wet and lasts from November to April. The warmest months are January and February with average temperatures of $35{ }^{\circ} \mathrm{C}$ in the lowlands and $32{ }^{\circ} \mathrm{C}$ on the central plateau. The problem with warm weather is that cyclones are frequent. Cyclones, with strong winds and heavy rain, can occur between November and April. Mauritius will normally experience about three or four cyclones a year during this period, each usually lasting two to three days. Winter season, which is influenced by the south-east trade wind, is from May to October. During this period the weather is cool and dry. The average temperature is $22{ }^{\circ} \mathrm{C}$ in the lower parts of Mauritius and $16{ }^{\circ} \mathrm{C}$ on the plateau and Plaines Wilhems. Rainfall ranges from $90 \mathrm{~cm}$ per year in the western lowlands to $500 \mathrm{~cm}$ in the central plateau with an average of $200 \mathrm{~cm}$ per year overall (Metz 1994). Humidity is frequently high in Mauritius and is above $80 \%$ in the south and the central plateau. Hence, the effects of climate can be investigated to know the degree of signal degradation.

The original motivation for this work came from a report by Pather (2000), in which he described the penetration of digital television in Mauritius and how this would affect the life of people. He predicted at that time that analogue television broadcasting would become part of history and hence there would be no alternative than to venture within the digital arena. He added that interactive digital television and T-Services would form part of everyday life, as was the case for NTSC, SECAM and PAL fourty years ago. This new technology would give better quality of service (QoS) and would be more economical. 
Since the first proposal in 1990 for digital systems by General Instrument Corporation (GIS: Company History online n.d.), there has been significant development in this area. The United States, Europe and Japan developed their own standards between 1993 and 1994. In this work we constrain our attention on the DVB-T standard used in European countries and in Mauritius. The DVB-T standard was produced in 1997 following several measurements and testing by various projects. Digital television is now an integral part of the information superhighway that is being built to deliver large amounts of information at very low cost compared to analogue technology and can be fully integrated into completely digital transmission networks. Digital television can deliver more programs than traditional analog television over one transmission channel and can be manipulated and treated in various ways which were never possible with analog television. We can therefore store digital images on computers and discs and play them continuously over digital networks without signal degradation until a certain threshold value is reached. Pictures can be modified, compressed, stored and transmitted. One advantage of the digital format is that it can be integrated with telephone conversations as well as computer data and then transmitted from one network to other broadcast networks. Furthermore, any program can be stored on multimedia servers (soap and movie, fillers and jingles, advert, songs) and retrieved instantly for broadcast to a single or multiple viewers on demand.

However, having good Quality of Service (QoS) and cheaper services do not mean that the problems of transmission and reception of digital signal broadcasting are completely solved. A correctly-formatted DTV signal is exposed to various factors which can detriment the sound or picture quality before it reaches the intended customers. For that reasons, many organizations and researchers are working on various areas such as transmitter and antenna models, propagation and coverage failures, compression techniques and standards in order to overcome implementation problems in view of setting frameworks and standards for digital television implementation. In this study, we constrain our attention to propagation models, coverage areas and failures.

\section{Problem Statement}

Following the liberalisation of the airwaves by the Government of Mauritius in 2002 and the official launching of digital terrestrial television in October 2005, there are now more private radio companies and will, in the near future, be more private television companies operating in the country. The digital TV (DTV) signal, just like the analogue signal, suffers from noise giving rise to problems such as 'ghosts' or tidal effects. A decoder in general is able to tolerate loss in field strength. Independently of the threshold noise level that the decoder can tolerate, our aim is to design a propagation model such that the signal despite suffering from maximum attenuation does not go below the threshold level for the decoder, as once the bit error rate crosses $2 \times 10^{-4}$, a total loss of signal is obtained. The digital coverage, therefore, has to be studied to obtain good QoS.

In the coming decades, the number of channels which will beam into homes and the number of potential signal paths to the consumer will multiply. Due to a more sophisticated multichannel environment, there will be an even larger number of separate processes and switching stages through which a radio or television signal will pass and, at any moment, one signal may fail or detrimentally affect the picture or sound quality. Hence, the opportunity for faults and failures occurring between the broadcaster and the consumer is 
increasing. It will become more and more difficult for a broadcast engineer to know whether a signal, after passing through all these separate processes and transmission paths, will reach the consumer in a correct audio and picture format. An alternative solution to the problems needs to be found.

\section{Propagation Models}

\subsection{Overview}

The common approaches to propagation modelling include:

(i) Physical models

Physical models of path loss make use of physical radio waves principles such as free space transmission, reflection or diffraction.

(ii) Empirical models

Empirical models use measurement data to model a path loss equation. Examples of empirical propagation models include the ITU-R and the Hata models. Empirical models use what are known as predictors or specifiers in general statistical modelling theory (Saunders 2005). To conceive these models, a correlation was found between the received signal strength and other parameters such as antenna heights, terrain profiles etc through the use of extensive measurement and statistical analysis.

Prediction of path loss is an important element of system design in any communication system. In the radio and TV broadcast systems, the prediction of path loss is very important as the environment is constantly changing with time. The question that is always asked is how to calculate the path loss with maximum accuracy. One solution is to use a propagation model. A reliable propagation model is one which calculates the path loss with small standard deviation. This will, hence, help network engineers and planners to optimise the cell coverage size and to use the correct transmitted powers. Suitable models must be chosen for prediction. An accurate and reliable prediction method helps to optimize the coverage area, transmitter power and eliminates interference problems of other radio transmitters. All the prediction methods are divided into empirical and deterministic/physical models.

The choice of the coverage prediction model depends on the propagation environment and the coverage area. In communications, propagation takes place through multiple diffraction, reflection and scattering among others from an extremely large number of objects. Since it is very difficult to locate scatterers deterministically, characterisation of the signal within the coverage zone is done statistically. For this reason, prediction models have been developed using empirical or statistical methods. The accuracy of a particular model in a given environment depends on the fit between the parameters required by the model and those available for the area concerned (Rama Rao et al. 2000). Examples of these models are Ikegami (Tapan et al. 2003), Ibrahim and Parsons (Tapan et al. 2003), Free-Space (Friis 1946 cited in Saunders 205 and Tapan et al. 2003), Extended COST-231 (COST 231 Final Report 1999 cited in Tapan et al. 2003), Perez-Vega and Zamanillo's model (Perez-Vega and Zamanillo 2002), Plane Earth Loss (Perez-Vega and Zamanillo 2002), Hata model (Hata 1980), Lee model (Lee 1985), COST231 Walfisch-Ikegami model (Ikegami et al. 1984), Walfisch-Bertoni model (Walfisch and Bertoni 1988), and ITU-R (ITU Report 1998, p.370). 


\subsection{Applications of Propagation models}

The prediction techniques or models described in this study are most often implemented for practical planning within computer software. The development of such software has been motivated and enabled by a number of factors (Saunders 2005):

(i) The enormous increase in the need to plan digital broadcast systems for TV services and cellular systems accurately and quickly

(ii) The development of fast and affordable resources

(iii) The development of graphical information systems, which index data of terrain, clutter and land usage in an easily accessible and manipulated form giving better frequency management etc.

Such techniques have been implemented in a wide range of commercially available and company-specific planning tools. Some of the prediction tools are listed in Table 1. Although most are based on combined empirical and simple physical models, it is anticipated there will be a progressive evolution in the future towards more physical or physical-statistical models as computing resources becomes cheaper and cheaper, as clutter data improves in resolution and as researchers develop more efficient path loss prediction algorithms.

\begin{tabular}{|l|l|}
\hline \multicolumn{1}{|c|}{ Tools } & \multicolumn{1}{|c|}{ Description } \\
\hline PACE & $\begin{array}{l}\text { The original propagation systems is now integrated into Vodafone Geographical } \\
\text { Information System }\end{array}$ \\
\hline ASTRIX & $\begin{array}{l}\text { Advanced SysTem for RadioInterface eXploration is intended for macrocells. It } \\
\text { incorporates path loss models Okumura-Hata, Blomquist-Ladell, Walfisch-Bertoni and } \\
\text { diffraction loss models Deygout and Epstein-Peterson. It treats also 3D terrain } \\
\text { scattering. }\end{array}$ \\
\hline PathPro & $\begin{array}{l}\text { It treats propagation models COST 231 microcell and macrocell, Hata and Longley- } \\
\text { Rice. }\end{array}$ \\
\hline CelPlanner & $\begin{array}{l}\text { It incorporates propagation models Lee-Picquenard, Okumura-Hata, COST 231 and } \\
\text { Korrowajczuk. }\end{array}$ \\
\hline Planet & It incorporates the propagation model UK Army EMC Agency PR03. \\
\hline NetPlan & $\begin{array}{l}\text { It incorporates propagation models Okumura-Hata and Walfisch-Ikegami. } \\
\text { Xia }\end{array}$ \\
\hline
\end{tabular}

Table 1: Prediction Tools (Source from Saunders 2005)

\subsection{Survey of various propagation models and their technical background}

The two basic propagation models (Free-Space and Plane Earth Loss) have all the mechanisms which are encountered in macrocell prediction. Many researchers use these models and predict the total signal loss. Other models require detailed knowledge of the location, dimension and parameters for every tree or building and terrain feature in the area to be covered. The models are complex and yield an unnecessary amount of details as the network designer is not interested in the particular locations covered, but the overall extent of the coverage area. One appropriate way of removing these complexities is to adopt an empirical model. These models use, as parameters, the received signal strength, frequency, antenna heights and terrain profiles, derived from a particular environment through the use of extensive measurement and statistical analysis. The models can then be used to design systems operated in similar environments to the original measurements. 


\subsubsection{The Okumura-Hata model}

The simple modeling of path loss is still dominated by the Hata empirical model (Hata 1980), where the propagation results are fitted to a simple analytical expression, which depends on antenna height, environment, frequency and other parameters. Hata's method is basically an extension of Okumura's method (which is somewhat cumbersome due to numerous correction factors) and employs propagation curves instead of parametric equations. It is a model based upon an extensive series of measurements made in and around Tokyo city between $200 \mathrm{MHz}$ and $2 \mathrm{GHz}$. Predictions are made via a series of graphs. The thoroughness of work has made the model the most widely used macrocell prediction model and is often regarded as a standard against which researchers can benchmark new approaches. The model for urban areas has been standardised in 1997 for international use as Rec ITU-R P.529 model (ITU Report 1997). The Hata model does not have any of the path-specific corrections which are available in Okumara's model. Okumura takes urban areas as a reference and applies correction factors for conversion to the classification of terrain. Hence the model will involve dividing the prediction area into a series of clutter and terrain categories as follows:

(i) Open area: Open space, no tall trees or buildings in path, plot of land cleared for 300-400 m ahead, e.g. farm land, rice fields, open fields;

(ii) Suburban area: Village or highway scattered by trees and houses, some obstacles near the receiving antenna but not very congested;

(iii) Urban area: Build up city or large town with buildings and houses with two or more storages, or larger villages with close houses and tall and thickly grown trees.

The negative side of the Okumura-Hata model is that it is valid only for frequency between $150 \mathrm{MHz}$ and $1500 \mathrm{MHz}$, with base antenna height between $30 \mathrm{~m}$ to $200 \mathrm{~m}$ and receiving antenna between $1 \mathrm{~m}$ and $10 \mathrm{~m}$. However, this model will not be a problem to use in this research as measurements are taken within the ranges mentioned above. Another problem encountered by this model is that in some countries measurements have been in disagreement with the predictions. The reason cited is the difference in characteristics of Tokyo city. Kozono and Watanabe (1977) have tried to modify the model by including a measure of building density, but such approach has not found common acceptance. The third problem is that the model has been developed for only three categories of land usage (rural, sub-urban and urban) as in practice the classification of land usage of a country (e.g. Mauritius, England, India) can exceed 10 categories.

\subsubsection{Other Standard Models}

In this study, the Lee model (Lee 1985), and the approximate model Extended COST 231Hata (COST 231 Final Report 1999 cited in Rama Rao 2000) are considered apart from the Hata and Free Space model as explained in the previous section. Approximate models COST 231/Walfisch-Ikegami (1984) and Walfisch-Bertoni (1988) have some restrictions because they do not include information on the environment. Hence, the risk of incorrect prediction is high since there are no correction factors for conversion according to the terrain classification. Moreover, COST 231/Walfisch- Ikegami model is valid for frequency between 800 and $2000 \mathrm{MHz}$, that is, it is not applicable to macrocells but to microcells. In a later stage in 1999, COST 231 was improved and a new model was created which is adopted for various terrains. The model which was derived from Hata is known as Extended COST 
231-Hata model (COST 231 Final Report 1999). The Walfisch-Bertoni model considers the impact of rooftops and building height by using diffraction to predict average signal strength at street level. These methods describe urban propagation loss as a sum of three terms: free space losses, rooftop to street losses and multiple diffraction losses. The approaches of Walfisch-Ikegami and Walfisch-Bertoni are restricted by definition to radio paths that are obstructed by buildings. The models account for local terrain slope in the vicinity of the receiving antenna and do not incorporate terrain roughness factors and do not treat obstructing terrain features such mountains and gorges. Finally, the empirical model developed by Blomquist-Ladell (1974) has some limitation since it includes only the sum of free space loss, the sum of smooth spherical earth loss, obstacle diffraction loss, urban loss and vegetation loss. It does not include loss due to reflection, climates and seasons.

Research on propagation models and path loss have been carried out in the past by several researchers like Grosskopf (1987) in Germany, Rama Rao et al. (2000) and Prasad (2006) in India, The Perez-Vega-Zamanillo (2002) in Spain and Hosseinzadey (2003) in Iran among may others. The Perez-Vega-Zamanillo model is a simple propagation model for the VHF and UHF bands. The model is a computational form of the data provided by the FCC $\mathrm{F}(50,50)$ propagation curves. The model is not frequency dependent in the band of interest and can be used to predict the path-loss for television broadcasting. One disadvantage is that it does not provide information on issues such as fade margins, angles of arrival, or delay spread, which must be estimated by another way.

The model developed by Grosskopf (1987) has no classification of urban, suburban and open areas or correction factors which are very important for a model. His technique is to predict path loss for only hilly and mountainous land in Germany. Prasad (2006) has done intensive work where field strength measurements are taken over Indian subcontinent and the calculated path loss is compared with other models including the Perez-Vega-Zamanillo (2002) one. However, no model was proposed from the observations and results.

\subsection{Factors to improve accuracy of models}

Below are factors that can be considered to improve accuracy of propagation models:

(i) Reflection is the result of digital TV signal hitting on obstructions with properties (thickness, length) much larger than the wavelength of the radio wave (e.g. smooth surface of walls and hills/mountains).

(ii) Diffraction occurs when radio waves strikes the edges or corners of obstacles. These act as secondary sources re-radiating into the shadow region. It is due to the diffraction effect that radio frequency energy travels in dense urban environments where there is no clear Line-of-Sight between two antennas (e.g. from edges such as building rooftops and mountaintops).

(iii) Scattering occurs when the properties of the object interacting with the radio wave is on the order of the colliding wavelength (e.g. from rough surfaces such as sea, rough ground and the leaves and branches of trees).

(iv) Absorption (e.g. by walls, foliage and by atmosphere)

(v) Refraction (e.g. due to atmospheric layers or layered and graded materials)

(vi) The directional characteristics of both the transmitter and the receiver antennas. (Saunders 2005).

All these factors are called multiplicative noise. It is more conventional to subdivide these factors as path loss, shadowing or slow fading and fast fading or multipath fading. 


\section{Shadowing}

Shadowing is the loss of field strength typically contributed to a diffracted wave emanating from an obstacle between transmitter antenna and receiver antenna (Saunders 2005). As passing through a shadow area requires considerable time, the name 'slow fading' is commonly used. The shadow effect is modeled with a log-normal distribution of the mean signal.

\section{Fast Fading (Multipath Propagation)}

As radio waves are reflected or diffracted or scattered by trees, hills and mountains, buildings and other obstacles, they establish various transmission paths from the transmitter to the receiver antennas. Many reflections are produced in an urban environment and few reflections in rural areas. The multipath creates the most difficult problem in the digital broadcast environment.

\subsection{The Technical Background of Propagation Models}

This section provides methods for predicting path loss used in macrocells (above $1 \mathrm{~km}$ ). The models presented here treat the path loss associated with a given macrocell as dependent on distance between a transmitter and a receiver, provided that the environment is fairly uniform. The free space propagation model is discussed briefly whereas the plane earth loss model is not treated in this work as the latter will require detailed knowledge of the location, dimension and constructive parameters of every tree, building and terrain feature in the area to be covered. It will be too complex and will yield an unnecessary amount of details since the broadcasting designer, network engineer and planner will not be interested in the particular locations being covered, but rather in the overall extent of the coverage area (Saunders 2005).

In the design of any broadcasting system, the fundamental task is to predict the coverage of the proposed system. Digital television service coverages are characterised by a very rapid transition from near perfect reception to no reception at all (Smith 2003). Hence, it becomes critical to be able to define which areas are going to be covered and which are not. As it is the case for Mauritius, it becomes necessary to increase the transmitter powers or to provide a large number of transmitters in order to guarantee coverage to the last few percent of the worst served small areas.

A wide variety of techniques have been developed over the years to predict coverage using what are known as propagation models (Saunders 2005). Propagation, in this context, means the transmission of signals from the transmitter to the receiver. En route from the transmitter to the receiver, the signal gets weaker and may experiences shadow or multipath effects (Ong et al 2004).

As said by Saunders (2005), based on the path loss information, to improve reception in a particular situation the following factors can be considered:

(i) Use a more directional receiving antenna with a higher gain

(ii) Find a better position for the receiver-antenna

(iii) Use of a low-noise antenna amplifier (as in the case of fixed antenna reception).

In general terms, path loss occurs when the transmitted signal suffers a loss proportional $1 / R^{2}$, where $\mathrm{R}$ is the distance between transmit and receive antennas. 


\subsubsection{Free Space Propagation Model}

The free space propagation model is used to predict received signal strength when the transmitter and receiver have a clear, unobstructed line-of-sight path between them (Friis 1946). As with most large-scale radio wave propagation models, the free space model predicts that received power decays as a function of the Transmitter-Receiver separation distance raised to some power (i.e. a power law function) (Saunders 2005).

The free space power received by a receiver antenna which is separated from a radiating transmitter antenna by a distance d, is given by the Friis free space equation (Friis 1946),

$$
P_{r}(d)=\frac{P_{t} G_{t} G_{r} \lambda^{2}}{(4 \pi)^{2} d^{2}}
$$

where $P_{t}$ is the transmitted power, $P_{r}(d)$ is the received power, $G_{t}$ is the transmitter antenna gain, $G_{r}$ is the receiver antenna gain, $d$ is the T-R separation distance in meters and $\lambda$ is the wavelength in meters.

The Friis free space equation shows that the received power falls off as the square of the Transmitter-Receiver (T-R) separation distance. This implies that the received power decays at a rate of $20 \mathrm{~dB} /$ decade with distance.

The path loss, which represents signal attenuation as a positive quantity measured in $d B$, is defined as the difference (in $\mathrm{dB}$ ) between the effective transmitted power and the received power, and may or may not include the effect of antenna gains(ITU Report 1998).

The path loss for the free space model when antenna gains are included is given by:

$$
\begin{aligned}
P L(d B) & =10 \log \frac{P_{t}}{P_{r}} \\
& =-10 \log \left[\frac{\mathrm{G}_{\mathrm{t}} \mathrm{G}_{\mathrm{r}} \lambda^{2}}{(4 \pi)^{2} d^{2}}\right]
\end{aligned}
$$

Equation (3.2) can be expanded to give an equation in terms of distance, $\mathrm{d}(\mathrm{km})$ and frequency of operation, $f(\mathrm{MHz})$ :

$$
\begin{aligned}
P L(d B) & =-10 \log _{10}\left(G_{t}\right)-10 \log _{10}\left(G_{r}\right)-20 \log _{10}\left[\frac{\left(c \times 10^{-3}\right)}{4 \pi \times f \times 10^{6}}\right]-20 \log _{10}(1 / d) \\
& =-G_{\mathrm{t}}(d B)-G_{r}(d B)+32.44+20 \log _{10}(d / k m)+20 \log _{10}(f / M H z)
\end{aligned}
$$

where $c$ is the speed of light $\left(3 \times 10^{8} \mathrm{~ms}^{-1}\right)$

\subsubsection{Okumura-Hata path loss model}

The Okumura-Hata model (1980) is an empirical formulation of the graphical path loss data provided by Yoshihisa Okumura, and is valid from $150 \mathrm{MHz}$ to $1500 \mathrm{MHz}$. The Hata model 
is, basically, a set of equations based on measurements and extrapolations from the curves derived by Okumura. Hata presented the urban area propagation loss as a standard formula, along with additional correction factors for application in other situations such as suburban and rural.

Only four parameters are required in the Hata model. Hence, the computation time is very short. This is an advantage of the model. However, the model neglects the terrain profile between the transmitter and receiver, that is, hills or other obstacles between the transmitter and receiver are not considered. This is because both Hata and Okumura made the assumption that the transmitters would normally be located on hills. Figure 1 shows a typical scenario for Hata-Okumura model.



Fig. 1. Scenario for Hata model

The above model assumes a direct line-of-sight path from transmitter $(t x)$ to receiver $(r x)$ but the actual path is obstructed by two hills. Hence, the prediction would be too optimistic.

The standard Hata formula for median path loss in urban areas is given by:

$$
\begin{aligned}
L(\text { urban })(d B)= & 69.55+26.16 \log f_{c}-13.82 \log h_{t x} \\
& -a\left(h_{r x}\right)+\left(44.9-6.55 \log h_{t x}\right) \log d
\end{aligned}
$$

where:

$f_{c}$ is the frequency (in $\mathrm{MHz}$ ) from $150 \mathrm{MHz}$ to $1500 \mathrm{MHz}$,

$h_{t x}$ is the effective transmitter antenna height (in m) ranging from $30 \mathrm{~m}$ to $200 \mathrm{~m}$,

$h_{r x}$ is the effective receiver antenna height (in $\mathrm{m}$ ) ranging from $1 \mathrm{~m}$ to $10 \mathrm{~m}$,

$d$ is the T-R separation distance (in $\mathrm{km}$ ),

$a\left(h_{r x}\right)$ is the correction factor for effective antenna height which is a function of the size of the coverage area.

To obtain the path loss in a suburban area, the standard Hata model formula in equation (3) is modified to:

$$
L(d B)=L(\text { urban })-2\left[\log \left(f_{c} / 28\right)\right]^{2}-5.4
$$

For a terrain category such as the north of Mauritius, the antenna correction factor is given by:

$$
a\left(h_{r x}\right)=\left(1.1 \log f_{c}-0.7\right) h_{r x}-\left(1.56 \log f_{c}-0.8\right) \quad \mathrm{dB}
$$




\subsubsection{Extended COST-231 Hata model}

This model (COST 231 Final Report 1999 cited in Tapan et al. 2003 and Zreikat and AlBegain n.d.) is derived from the Hata model and depends upon four parameters for the prediction of propagation loss: frequency, height of a received antenna, height of a base station and distance between the base station and the received antenna.

From equation (3), the urban model is given by:

$$
\begin{aligned}
L(\text { urban })(d B)= & 46.33+33.9 \log f_{c}-13.82 \log h_{t x} \\
& -a\left(h_{r x}\right)+\left(44.9-6.55 \log h_{t x}\right) \log d
\end{aligned}
$$

The path loss in a suburban area is given by:

$$
L(d B)=L(\text { urban })-2\left[\log \left(f_{c} / 28\right)\right]^{2}-5.4
$$

where $a\left(h_{r x}\right)$ is obtained from equation (4).

\subsubsection{Lee Model}

The Lee model (1985) is a power law model with parameters taken from measurements in a number of locations. The model is expressed as follows:

$$
L(\text { suburban })(d B)=10 n \log d-20 \log h_{t x}-P_{o}-10 \log h_{r x}+29
$$

where $n=3.84$ and $P_{o}=-61.7$. Here it has been assumed that $h_{t x}$ is the effective base station height.

\subsubsection{Rec ITU-R P.370 Propagation prediction method}

Prediction of the coverage provided by a given transmitting station is normally done on the basis of the field strength for the wanted signal predicted.

Rec ITU-R P.370 (ITU Report 1998) is a commonly agreed field strength method for broadcasting services. The propagation curves given in this recommendation represent field strength values in the VHF and UHF bands as a function of various parameters.

The power received at a distance $d, P_{r}$ is given by:

$$
\begin{aligned}
& P_{r}=\frac{|E|^{2}}{120 \pi} A_{e} \\
& P_{r}(d B)=20 \log _{10} E-10 \log _{10}(120 \pi)+10 \log _{10} A_{e} \\
& P_{r}(d B)=2 E_{\text {min }}-10 \log _{10}(120 \pi) / \Omega+A_{e}\left(d B m^{2}\right)
\end{aligned}
$$

where:

$E_{\min }$ is the equivalent minimum field strength at receiving place

$A_{e}$ is the effective antenna aperture $\left(\mathrm{dBm}^{2}\right)$

$120 \pi$ is the value of intrinsic impedance of free space (ohms). 
However, the above equation relates electric field (with units of $\mathrm{V} / \mathrm{m}$ ) to received power (with units of watts). Often, this equation is used to relate the received power level to a receiver input voltage, as well as to an induced electric field at the receiver antenna.

In situations where practical values of field strengths are available in $d B \mu V / m$ from measurements, the corresponding path loss in $\mathrm{dB}$ can be calculated as follows if the values for transmitted power and effective receiver antenna aperture are known:

$$
\begin{gathered}
P L(d B)=P_{t}(d B)-P_{r}(d B) \\
P L(d B)=P_{t}(d B)-E_{\min }-A_{e}(d B)+10 \log _{10}(120 \pi) \\
P L(d B)=P_{t}(d B)-2 E_{\min }(d B \mu V / m)+240-A_{e}(d B)+10 \log _{10}(120 \pi)
\end{gathered}
$$

where $E_{\min }=E_{\min }(d B \mu V / m)-120$.

\section{Comparative Field Strength and Path Loss Analysis - A Case Study}

\subsection{Data Collection, Experimental Details and Methodology}

Measurement locations are divided into three groups for each region, that is, three concentric circles CC1N, CC2N and CC3N for the north and CC1S, CC2S and CC3S for the south. The radius determines the horizontal distance between the measured point (receiver antenna) and the transmitter. The radii of CC1N/CC1S, CC2N/CC2S and CC3N/CC3S are $5 \mathrm{~km}, 10$ and $15 \mathrm{~km}$ respectively. Points are selected on the circles as shown in Figure 2 and determined the measuring sites. It should be noted that at each measuring site, three to four times, measurements were taken every five minutes for a period of 20 minutes. The exercise are conducted at 78 locations sites in the North ( 26 for CC1N, 26 for CC2N and 26 for CC3N) and at 99 locations sites in the South (33 for CC1S, 33 for CC2S and 33 for CC3S)

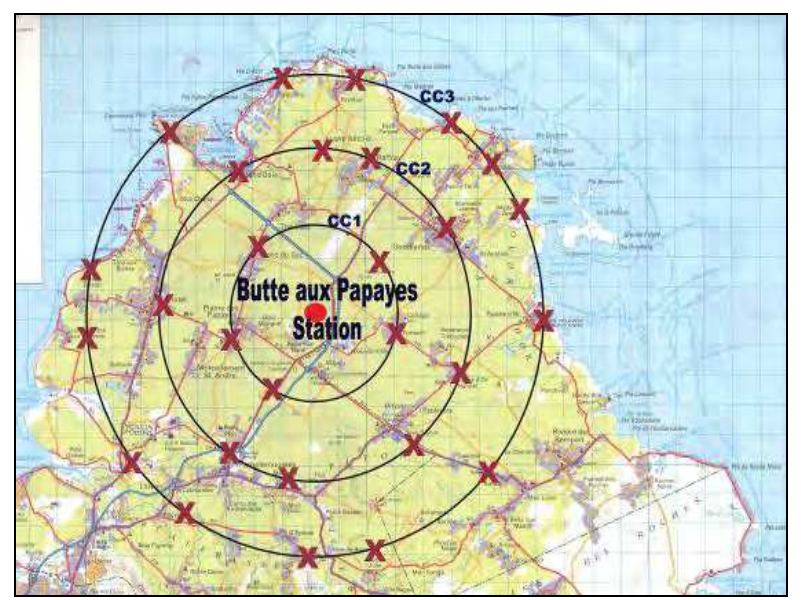

Fig. 2. View of one part of Mauritius 
A measuring vehicle is used to carry the equipment and the measurements are done manually. As shown in Figure 3, the vehicle is stopped at each site and the log periodic antenna from Fracarro (Antennas online 2007, Fracarro Antenna online 2007) is raised up to a height and is properly oriented towards the transmitter to achieve maximum signal strength. The measurements are conducted around the relay station and are repeated for two receiving antenna heights of $4 \mathrm{~m}$ and $6 \mathrm{~m}$. Once the received signal has been captured the field strength, the BER value, the minimum Carrier to Noise $(C / N)$ and CSI are recorded for digital TV signal. Measurements were taken at antenna heights $4 \mathrm{~m}$ and $6 \mathrm{~m}$.

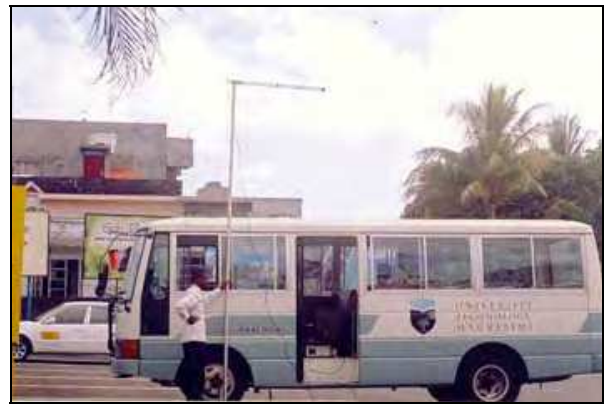

Fig. 3. The Measuring Vehicle

\subsection{Signal Strength and Interference}

The aim of this work is to study the variation of the received field strength, carrier-to noise and Bit Error Rate for different locations in the northern region of Mauritius (Fogarty, Soyjaudah and Armoogum 2006). Similar works have been carried out in various countries (India, Spain, Canada, Korea) as explained by Rama Rao et al. (2000), by Prasad (2006), by Arinda et al. (1999a, 1999b), by Assia Semmar et al. (2006), by Sung Ik Park et al. (2007) and more recently by Martinez et al. (2009). All these studies have analysed the quality of digital TV signal reception. In Mauritius, this exercise is important so as to give a realistic picture of the situation. Few measurements at UHF frequencies for digital television have been made. The experiment (Figure 4) shows that at a distance of $5 \mathrm{~km}$ the field strength is high enough (minimum threshold value is $53 \mathrm{~dB} \mu \mathrm{V} / \mathrm{m}$ ) for the COFDM component of the AFSM to decode picture to achieve a BER lower than $2 \times 10^{-4}$. For both regions, almost all locations will have high performance of digital transmission. For an ideal case, that is, a topography of flat earth with Line-Of-Sight propagation, the received field strength at all locations over concentric circle CC1 must be constant. At a distance of $10 \mathrm{~km}$ and more, the cell covered by the base station does not include all the measuring points since the received signal strength is less than $53 \mathrm{~dB} \mu \mathrm{V} / \mathrm{m}$ (the signal level and quality at some points are not high enough to decode the information stream). However, for both regions at a certain constant distance round the station, the graph obtained shows that the field strength is varying with location. This may be explained by the fact that due to Non Line-Of Sight (NLOS), there may be different diffraction losses due to different buildings in the north or due to dense forests and mountains (knife-edge) in the south in the path linking the base station and the location of interest. Multipath effects may also be the cause, giving rise to a graph of varying field strength with location. 
The field strength in the south decreases more than that of the north. Besides, when comparing the standard deviations, the $\mathrm{C} / \mathrm{N}$ deviates too much from the mean values in the south, indicating that there are more obstructions in the south. Though the south is classified as a rural area compared to the northern area (sub urban), there are more factors affecting the signal in that region.

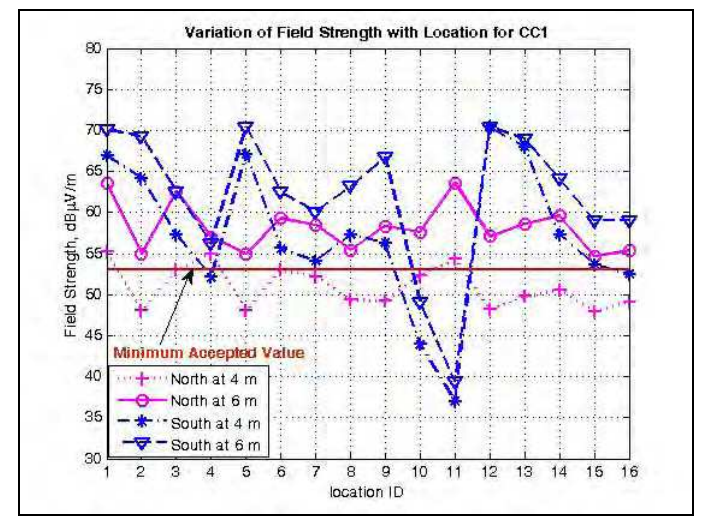

Fig. 4. Variation of Field strength for various antenna heights in the North and South at a distance of $5 \mathrm{~km}$ from transmitter

\subsection{Path Loss Analysis}

The main aim is to study the variation of the path loss at various locations in the south and compare them with those from the north (Armoogum et al. 2007a, Armoogum et al. 2007b). In theory, the path loss at a constant distance from a transmitter is the same for any point around it. For both areas, as depicted in Figure 5, the path loss is not constant at various locations for a constant distance around the transmitter which therefore indicates about the irregularity of both terrains of the island. The path loss for an antenna height of $6 \mathrm{~m}$ is lower than that of $4 \mathrm{~m}$ as a result of a reduction of multipath effects with a higher antenna.

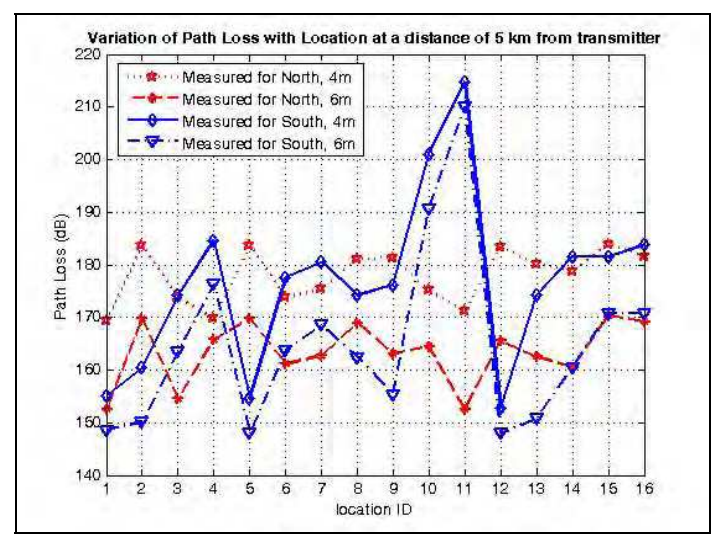

Fig. 5. Variation of Path Loss for both regions at $5 \mathrm{~km}$ from transmitter 


\subsection{Comparative Study of Pass Loss with Various Existing Propagation Models and Selecting the Best One(s)}

The measured pass loss is compared with models such as Free-Space, Okumura-Hata, Extended COST-231 and Lee. The aim is find out which of the model(s) gives/give better agreement with the measured pass loss. From figures Figure 6 and Figure 7, it is clear that the Lee model and the Free-Space model deviate too much from the measured values, which implies that these models are not suitable for modelling the south of Mauritius. For both regions, the path loss using Okumura-Hata model and Extended COST-231 are much closer to each other and give better agreement with the measured values. The slight difference between these two models can be considered negligible.

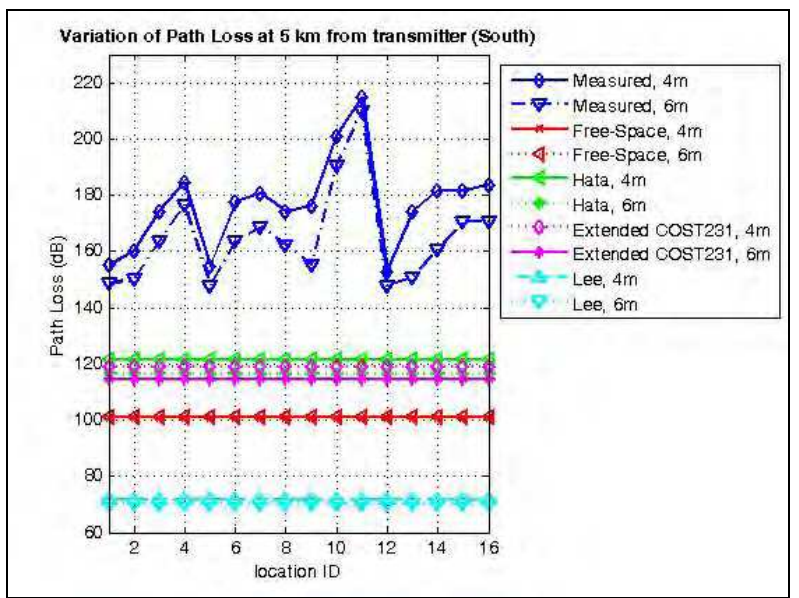

Fig. 6. Variation of Path Loss in the South using various propagation models at $5 \mathrm{~km}$ from transmitter

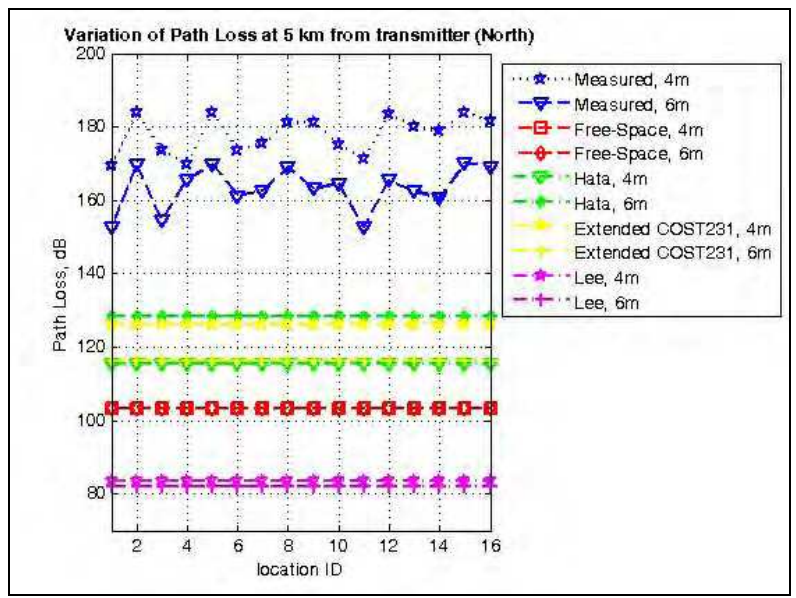

Fig. 7. Variation of Path Loss in the North using various propagation models at $5 \mathrm{~km}$ from transmitter 
There is no need to transform the two models into a discrete-time mode as the signal strength depends only upon the power transmitted and received. The results show that the analogue models can be used in digital broadcast systems. These models can be used to develop a novel digital model for Mauritius. Since the north and the south of Mauritius are inhomogeneous ones and consist of rural, sub-urban and urban areas unevenly located, we can take sub-urban areas as a reference and applies correction factors for conversion to the classification of terrain.

Using equations (3) and (3.1) from Section 3.5, the digital Hata-Okumura model is given by:

$$
\begin{aligned}
L(d B)=69.55+ & 26.16 \log f_{c}-13.82 \log h_{t x} \\
& -a\left(h_{r x}\right)+\left(44.9-6.55 \log h_{t x}\right) \log d-2\left[\log \left(f_{c} / 28\right)\right]^{2}-5.4
\end{aligned}
$$

Using equations (5) and (3.5.1) from Section 3.5, the digital Extended COST-231 Hata model is given by:

$$
\begin{aligned}
L(d B)=46.33+ & 33.9 \log f_{c}-13.82 \log h_{t x} \\
& -a\left(h_{r x}\right)+\left(44.9-6.55 \log h_{t x}\right) \log d-2\left[\log \left(f_{c} / 28\right)\right]^{2}-5.4
\end{aligned}
$$

\section{Proposed way for Modelling Broadcast Networks}

The best way to design new broadcast networks or optimize existing networks is to develop new models or improving existing ones. This section provides a new definition for the types of terrain of Mauritius (a case study) and secondly proposed the techniques that could be used in developing new models.

\subsection{Redefining the Classification of Land Usage for Mauritius}

The first problem with the empirical models is the classification of environment in which the system is operating. Once the real classification through the analysis parts is known, better results are obtained if the appropriate category of terrain is reviewed. The categories must be numerous so that the properties of different locations classed within the same category are not too variable. A proposed definition of categories is depicted in Table 2.

\subsection{The Approaches}

The two empirical models stated in Section 4 are fundamental for the prediction of path loss. The new models may thus be developed as means of improving accuracy using two approaches: deterministic empirical-physical approach or empirical-statistical approach using some statistical parameters.

What are Physical and Statistical approaches?

The physical approach:

A Digital TV wave signal can be reflected or refracted when hitting a surface. In these cases the Snell's laws of reflection and refraction will be applied. Rays can hit different types of surface. In Mauritius, there are dry land, average ground, wet ground, sea water and fresh 
water and the reflection will differ according to the conductivity and relative dielectric constant. These values are available in ITU Report-527 (ITU Doc. 1992). These reflection processes are so far applicable to smooth surfaces and are termed specular reflection. When the surface is rougher, the reflected signals become scattered from a larger number of positions on the surface, hence, reducing the field strength and increasing the attenuation. Refraction also occurs due to atmospheric layers. A higher permittivity (the denser medium) causes the transmitted signal to bend more toward the surface normal. This change of direction changes the velocity of the signal with respect to refractive index and might cause delay spread. In many situations in Mauritius, diffraction over obstructions such as hills, mountains and buildings may be treated as if they are absorbing knife-edges (single knifeedge and multiple knife edge diffraction). Using physical approach means modelling all the above factors.

\section{The statistical approach:}

The region is divided into small homogeneous areas and categories. The smaller the sector, the more homogeneous will be the area. A forecasting technique is used to predict path loss from 0 to $15 \mathrm{~km}$ (interpolation) and above (extrapolation). Mathematical equations are derived for each homogeneous area. Finally, a general Mathematical equation is derived for similar homogeneous areas, that is, for a specific category of land.

For the development of novel models, it is believed that the empirical-statistical approach is better for the following reasons

(i) The physical approach will lead to entirely incorrect predictions when considering fields in the shadow region behind an obstruction.

(ii) Using the physical approach, it would be very difficult to get the exact parameters of obstructions (size of buildings, heights, distance between buildings, density of forests, types of soil etc).

(iii) The empirical-statistical model is more economical as the physical models involve a large number of expensive input data requirements.

\begin{tabular}{|c|l|}
\hline Category & \multicolumn{1}{|c|}{ Details } \\
\hline 0 & Reservoirs, Lakes and Sea ${ }^{\text {. }}$ \\
\hline 1 & Open Rural Area with Plantation (Sugar cane and Tea). \\
\hline 2 & Open Rural Area with Forest in between. \\
\hline 3 & Dense Forested Area. \\
\hline 4 & Mountainous region \\
\hline 5 & Hilly and Mountainous Forested Area. \\
\hline 6 & $\begin{array}{l}\text { Sub Urban Area - Small villages }{ }^{2} \text { of low-density houses of up to two storeys, with } \\
\text { some open areas and trees. }\end{array}$ \\
\hline 7 & $\begin{array}{l}\text { Sub Urban Area - Big villages }{ }^{3} \text { with houses of up to two storeys and industries } \\
\text { industrial zones) and with some open space and trees in between. }\end{array}$ \\
\hline 8 & Urban Area - Big villages or towns with buildings of up to four storeys \\
\hline 10 & $\begin{array}{l}\text { Higher Urban Area - Town }{ }^{4} \text { with buildings of up to four storeys and closed to each } \\
\text { other. }\end{array}$ \\
\hline 11 & $\begin{array}{l}\text { Dense Urban Area - Town with buildings very closed to each other in which some of } \\
\text { them are up to eight storeys. }\end{array}$ \\
\hline $\begin{array}{l}\text { Very Dense Urban Area - Big town or cities }{ }^{5} \text { with buildings very closed to each other } \\
\text { in which most of them are eight storeys and above. }\end{array}$ \\
\hline
\end{tabular}

Table 2. Classifications of Land Usage for Mauritius 


\section{Conclusion}

The increasing demand of various fixed and mobile services has placed considerable pressure on the limited frequency spectrum. For the efficient utilisation of this resource, as well as for performance assessment of the existing systems, modeling and coverage predictions are essential. A reliable model of predicting path loss helps in reducing load on base stations and helps in designing digital broadcasting networks including TV services. We have considered Mauritius Island as a case study. From the observations and results obtained, it is concluded that the existing empirical models are not accurate and therefore cannot be used in Mauritius since the focus here is on small area propagation and for tropical, mountainous regions. The first limitation of existing models is that they are developed for limited categories of land (open area, sub-urban and urban areas). The table of classification of land usage was defined for Mauritius. For qualitative classification, the categories are numerous so that the properties of different locations classed with the same category are not too variable. Analysis and comparisons of field strength and height gain analysis in North and South were conducted to find out the types of terrain of Mauritius and the reasons why TV signals suffer a loss. The path loss analysis was conducted and tested using several models. Extended COST-231 and Okumura-Hata give better agreement in regions of Mauritius. Before developing novel models, the regions were divided into small homogenous areas and categorised. Two techniques are proposed for the development of new propagation models.

\section{Future Work}

In section 5, the technicalities toward the development of new models are not discussed. Then, performance analysis and testing need to be done using new measured data. The usual goal of performance analysis and testing is to determine the places of Mauritius where the models work properly and the places there are high deviations. An extensive work needs to be conducted for this purpose.

Models are widely used in prediction tools such as ASTRIX or CRUMPET. Computer applications have to be developed for the prediction of path loss, the designing of broadcast networks or optimizing existing network.

Some of the functionalities of these software tools with the integrated models are as follows:

(i) Design new broadcast networks,

(ii) Perform coverage prediction for various types of communication systems in order to design optimize networks of transmitters,

(iii) Analyze interference problems,

(iv) Explore new coverage scenarios,

(v) Diagnose difficult coverage situations,

(vi) Evaluate new transmitter and receiver concepts.

(vii) Visualize and analyze predicted performance, as well as compare simulation with experimental data.

Finally, to obtain a high quality image, these applications can be used with a geographical information system (GIS) storing the geographical locations of points for every $10 \mathrm{~m}^{2}$ and their corresponding categories as the main fields. 


\section{References}

Anderson, J. 2005. Digital Transmission Engineering. 2nd Edition. Wiley Publication.

Antenna [Online] 2001. Available at www.fracarro.com/NR/rdonlyres/7456FB27-45EF489D-8373-F8E23BB3CCAD/0/Antennas.pdf. [Accessed 2007].

Armoogum, V. Soyjaudah, K.M.S. Mohamudally, N. and Fogarty, T. 2007. Height Gain Study for Digital Television Broadcasting at UHF Bands in two Regions of Mauritius. Proceedings of the 2007 Computer Science and IT Education Conference, pp. 017-025, ISBN 9789990387476.

Armoogum, V. Soyjaudah, K.M.S. Mohamudally, N. and Fogarty, T. 2007. Comparative Study of Path Loss with some Existing Models for Digital Television Broadcasting for Summer Season in the North of Mauritius at UHF Band. IEEE The Third Advanced International Conference on Telecommunications (AICT-07), ISBN 0-76952443-0.

Armoogum, V. Soyjaudah, K.M.S. Mohamudally, N. and Fogarty, T. 2007. Path Loss Analysis between the north and the south of Mauritius with some Existing Models for Digital Television Broadcasting for Summer Season at UHF Bands. Proceedings of the $8^{\text {th }}$ IEEE AFRICON 2007, ISBN 0-7803-8606-X.

Arrinda, A. Ma Velez, M. Angueira, P. de la Vega, D. and Ordiales, J. L. 1999. Digital Terrestrial Television (COFDM 8k System) Field Trials And Coverage Measurements In Spain. IEEE Transactions On Broadcasting, 45(2), No. 2, pp. 171176.

Arrinda, A. Ma Velez, M. Angueira, P. de la Vega, D. and Ordiales, J. L. 1999. Local-Area Field Strength Variation Measurements Of The Digital Terrestrial Television Signal (COFDM 8k) In Suburban Environments. IEEE Transactions On Broadcasting, 45(4), pp. 386-391.

Assia Semmar, Jean-Yves Chouinard, Viet Ha Pham, Xianbin Wang, Yiyan Wu, and Sébastien Laflèche 2006. Digital Broadcasting Television Channel Measurements and Characterization for SIMO Mobile Reception. IEEE Transactions On Broadcasting, 52(4), pp. 450-463.

BBC 1998. AC106 Verification and Launch of Advanced Television in Europe (VALIDATE), Project Report.

Blomquist, A. and Ladell, L. 1974. Prediction and calculation of transmission loss in different types of terrain, FOA report.

CEPT 1997. The Chester 1997 Multilateral Coordination Agreement relating to Technical Criteria, Coordination Principles and Procedures for the introduction of Terrestrial Digital Video Broadcasting (DVB-T).

COST 231 Final Report 1999. Digital Mobile Radio: COST 231 View on the Evolution Towards $3^{\text {rd }}$ Generation Systems, Commisiion of the European Communities and COST Telecommunications, Brussels.

ETSI (European Te1ecommunications Standards Institute) 1997. Digital Video Broadcasting (DVB), Framing structure, Channel coding and Modulation for Digital Terrestrial Television (DVB-T), ETS 300744.

ETSI (European Te1ecommunications Standards Institute) 1997. Digital Video Broadcasting (DVB), Implementation guidelines for DVB services. Transmission aspects, ETS 101 190. 
Fogarty, T. Soyjaudah, K.M.S. and Armoogum, V. 2006. Signal Strength Variation Measurements of Digital Television Broadcasting for Summer Season in the North of Mauritius at UHF Bands, Conference Proceeding of the $3^{\text {rd }}$ International Conference on Computers and Device for Communication, pp. 89-92.

Fracarro Antenna [Online] 2001. Available at www.tvantenna.com.au /FARCARRO\%20ANTENNAS [Accessed 2007].

Friis, H.T. 1946.The Free Space Transmission equation. Proc. IRE, vol. 34, p.254.

Gaudrel, R. Betend, C. 1997. DIGITAL TV BROADCAST Field Trials on the Experimental Network of Rennes, Internal VALIDATE document from CCETT, FT.CNET/DMR/DDH.

GIS Company History [Online] n.d. Available at http://www.fundinguniverse.com /company-histories/General-Instrument-Corporation-Company-History.html, [Accessed on June 2006].

Grosskopf, R. 1987. Comparison of different methods for the prediction of the field strength in the VHF range. IEEE Trans. Ant. Propagation, 35(7), pp. 852-859.

Hata, M. 1980. Empirical formula for propagation loss in land mobile radio services. IEEE Trans. Veh. Technol., 29(no issue number), pp. 317-325.

Homayoon, O. and Shahram Hosseinzadeh 2003. Determination of the effect of Vegetation on Radio wave Propagation by the Parabolic Equation Method, Proceeding of 2 nd International Symposium of Telecommunications, IST2003, pp.340-344 Isfahan Iran.

Ikegami, F. Yoshida, S. Takeuchi, T. and Umehira, M. 1984. Propagation factors controlling mean field strength on urban streets. IEEE Trans. Ant. Prop., vol. 32 (no issue number), pp. 822-829.

International Telecommunication Union, ITU-R recommendation P.529-2 1997. Prediction methods for the terrestrial land mobile service in VHF and UHF bands.

International Telecommunication Union, ITU-R recommendation P.370 1998. Prediction methods for the terrestrial land mobile service in VHF and UHF bands, 1998.

International Telecommunication Union 1992. ITU-R Recommendation 527-3: Electrical Characteristics of the surface of the Earth, Geneva 1992.

ITU Geneva 1989. Final Acts of the Regional Administrative Conference for the Planning of VHF/UHF Television Broadcasting in the African Broadcasting Area and Neighbouring Countries.

Kozono, S. Watanabe, K. 1977. Influence of Environmental buidings on UHF Land mobile radio propagation, IEEE Trans. Commun., 25(10), pp.1133-1143.

Lee, W.C.Y. 1985. Estimation of local average power of a mobile radio signal. IEEE Trans. Veh. Technol., 34(1), pp. 22-27.

Martínez, A. Zabala, D. Peña, I. Angueira, P. Vélez M.M. Arrinda, A. de la Vega, D. and Ordiales, J.L. 2009. Analysis of the DVB-T Signal Variation for Indoor Portable Reception. IEEE Transactions On Broadcasting, 55(1), pp. 11-19.

Metz H. C., [Online] 1994. Ed. Mauritius: A Country Study. Washington: GPO for the Library of Congress, 1994. Available at http://countrystudies.us/mauritius/7.htm [Accessed on May 2006].

Ong, J. T. Rao, S. V. B. Shanmugam, G. Hong Y. 2003, Results of the Mobile DTV Measurements in Singapore, Nanyang Technological University, Singapore, Conference Publication. 
Ong, J.T. Rao, S.V.B. Hong Y. Shanmugam, G. 2004. Height Gain Measurements for DTV Reception in Singapore. IEEE Transactions On Broadcasting, 50(4), pp. 396-398.

Pather, A. August 2000. The move to Digital Broadcasting - Challenges Ahead, MultiCarrier (Mauritius) Limited.

Parsons, J.D. and Ibrahim, M.F. 1983. Siganl strength prediction in built-up areas-Part 2: Siganl variability. IEE Proc., vol. 130, no. 5, pp. 385-391.

Perez-Vega, C. and Zamanillo, J.M. 2002. Path Loss Model for Broadcasting Applications and Outdoor Communication Systems in the VHF and UHF Bands. IEEE Transactions On Broadcasting, 48(2), pp. 91-96.

Prasad, M.V.S.N. 2006. Path Loss Deduced From VHF and UHF Measurements Over Indian Subcontinent and Model Comparison. IEEE Transactions On Broadcasting, 52(3), pp. 290-298.

Prasad, M.V.S.N. and Iqbal, A. 1997. Comparison of some Path Loss Prediction Methods with VHF\&UHF Measurements. IEEE Transactions On Broadcasting, 43(4), pp. 459486.

Rama Rao, T. Vijaya Bhaskara Rao, S. Prasad, M.V.S.N. Mangal Sain, Iqbal, A. and Lakshmi, D. R. 2000. Mobile Radio Propagation Path Loss Studies at VHF/UHF Bands in Southern India. IEEE Transactions On Broadcasting, 46(2), pp. 158-164.

Regional Radiocommunication Conference for planning of the digital terrestrial broadcasting service (RCC-04). ITU-R Report, Geneva 2004.

Saunders, S. R. 2005. Antenna and Propagation for Wireless Communication Systems. Wiley.

Smith, D. 2003. Digital Transmission Systems. 3rd Edition. Kluwer Academic Publishers.

Sung Ik Park, Yong-Tae Lee, Jae Young Lee, Seung Won Kim, and Soo In Lee 2007. Field Test Results of the E-VSB System in Korea, IEEE Transactions On Broadcasting, 53(1) pp. 14-22.

Tapan, K. S. Zhong, J. Kyungjung, K. Abdellatif, M. and Magdalena Salazar-Palma 2003. A Survey of Various Propagation Models for Mobile Communication. IEEE Antennas and Propagation Magazine, 45(3), No. 3.

Walfisch, J. Bertoni, H. L. 1988. A Theoretical Model of UHF Propagation in Urban Environments. IEEE Transactions On Antennas And Propagation, 36(12), pp. 17881796.

Zreikat, A. and Al-Begain, K. n.d. Simulation of 3G Networks in Realistic Propagation Environments, I.J. of SIMULATION, 4(3\&4), ISSN 1473-804x online, 1473-8031. 


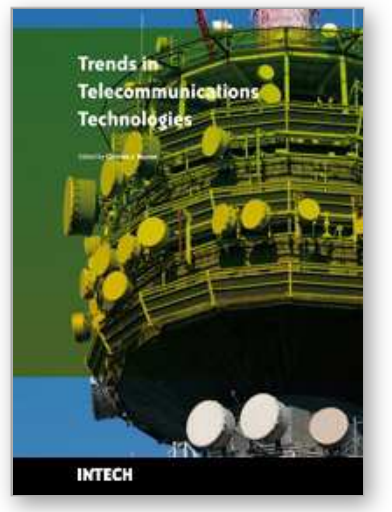

\author{
Trends in Telecommunications Technologies \\ Edited by Christos J Bouras
}

ISBN 978-953-307-072-8

Hard cover, 768 pages

Publisher InTech

Published online 01, March, 2010

Published in print edition March, 2010

The main focus of the book is the advances in telecommunications modeling, policy, and technology. In particular, several chapters of the book deal with low-level network layers and present issues in optical communication technology and optical networks, including the deployment of optical hardware devices and the design of optical network architecture. Wireless networking is also covered, with a focus on WiFi and WiMAX technologies. The book also contains chapters that deal with transport issues, and namely protocols and policies for efficient and guaranteed transmission characteristics while transferring demanding data applications such as video. Finally, the book includes chapters that focus on the delivery of applications through common telecommunication channels such as the earth atmosphere. This book is useful for researchers working in the telecommunications field, in order to read a compact gathering of some of the latest efforts in related areas. It is also useful for educators that wish to get an up-to-date glimpse of telecommunications research and present it in an easily understandable and concise way. It is finally suitable for the engineers and other interested people that would benefit from an overview of ideas, experiments, algorithms and techniques that are presented throughout the book.

\title{
How to reference
}

In order to correctly reference this scholarly work, feel free to copy and paste the following:

Armoogum V., Soyjaudah K.M.S., Mohamudally N., Fogarty T. (2010). Propagation Models and Their Applications in Digital Television Broadcast Network Design and Implementation, Trends in Telecommunications Technologies, Christos J Bouras (Ed.), ISBN: 978-953-307-072-8, InTech, Available from: http://www.intechopen.com/books/trends-in-telecommunications-technologies/propagation-models-andtheir-applications-in-digital-television-broadcast-network-design-and-impleme

\section{INTECH}

open science | open minds

\author{
InTech Europe \\ University Campus STeP Ri \\ Slavka Krautzeka 83/A \\ 51000 Rijeka, Croatia \\ Phone: +385 (51) 770447 \\ Fax: +385 (51) 686166 \\ www.intechopen.com
}

\author{
InTech China \\ Unit 405, Office Block, Hotel Equatorial Shanghai \\ No.65, Yan An Road (West), Shanghai, 200040, China \\ 中国上海市延安西路65号上海国际贵都大饭店办公楼 405 单元 \\ Phone: +86-21-62489820 \\ Fax: +86-21-62489821
}


(C) 2010 The Author(s). Licensee IntechOpen. This chapter is distributed under the terms of the Creative Commons Attribution-NonCommercialShareAlike-3.0 License, which permits use, distribution and reproduction for non-commercial purposes, provided the original is properly cited and derivative works building on this content are distributed under the same license. 